\title{
LÍNEAS BARTHESIANAS: APUNTES PARA PENSAR LA CIRCULACIÓN de Roland Barthes en ChILE*
}

BARTHESIAN LINES: NOTES ON THE CIRCULATION OF BARTHES'S IDEAS IN CHILE

Claudia Amigo Pino
ORCID 0000-0001-7311-316X

Francisca Lange ${ }^{2}$

ORCID 0000-0002-1292-4329

${ }^{1}$ Universidade de São Paulo, São Paulo, SP, Brasil

${ }^{2}$ Universidade Finis Terrae, Santiago de Chile, Chile

\section{Resumen}

El presente artículo explora la circulación de las obras Roland Barthes en Chile a partir del estudio de la crítica y de la narrativa del escritor Enrique Lihn (1929-1988). Para eso, abordamos, en primer lugar, la polémica de Lihn y el principal crítico chileno de la dictadura, José Miguel Ibãñez Langlois, en torno del estructuralismo francés. En segundo lugar, analizamos las marcas del pensamiento de Barthes en los textos críticos de Enrique Lihn reunidos en El circo en llamas. Finalmente, observamos cómo estas marcas también se reflejan en la narrativa de Lihn, específicamente en los relatos "Huacho y Pochocha", "Panorama artístico de la República Independiente de Miranda" y en las obras en que aparece el personaje Gerardo de Pompier.

Palabras-clave: Enrique Lihn, Roland Barthes, Crítica literaria chilena.

\section{Resumo}

Este artigo explora a circulação das obras de Roland Barthes no Chile a partir do estudo da crítica e da narrativa do escritor Enrique Lihn (1929-1988). Para isso, abordamos, em primeiro lugar, a controvérsia de Lihn e o principal crítico chileno da ditadura, José Miguel Ibãñez Langlois, sobre o estruturalismo francês.

\begin{abstract}
This article explores the circulation of Roland Barthes's works in Chile based on the study of writer Enrique Lihn's critic and narrative (1929-1988). To this purpose, we first address the differences in opinion between Lihn and the main Chilean literary critic during the dictatorship, José Miguel Ibãñez Langlois,
\end{abstract}

\footnotetext{
*Este texto es producto de una estancia de investigación junto al Instituto de Estética de la Universidad Católica de Chile en el primer semestre de 2020, bajo la supervisión de la profesora Lorena Amaro, a quien agradecemos por todo el apoyo prestado.
} 
Em segundo lugar, analisamos as marcas do pensamento de Barthes nos textos críticos de Enrique Lihn reunidos em El circo en llamas. Por fim, observamos como essas marcas também se refletem na narrativa de Lihn, especificamente nos contos "Huacho y Pochocha", "Panorama artístico de la República Independiente de Miranda" e nas obras em que o personagem Gerardo de Pompier aparece.

Palavras-chave: Enrique Lihn, Roland Barthes, Crítica literária chilena. regarding French structuralist theory. Second, we analyze the marks of Barthes's thought in Enrique Lihn's critical texts gathered in El circo en llamas. Finally, we observe how these marks are also reflected in Lihn's narrative, specifically in the stories "Huacho y Pochocha", "Panorama artístico de la República Independiente de Miranda" and in the works in which the character Gerardo de Pompier appears.

Keywords: Enrique Lihn, Roland Barthes, Chilean literary criticism.

Un notorio crítico francés, profesor del Collège de France, que muy poco escribió sobre obras literarias extranjeras y que nunca puso sus pies en América Latina. Un poeta chileno de vanguardia que no sabía hablar francés, a pesar de haber pasado dos estancias en Francia, y que fue fundamental para el campo literario en Chile durante la dictadura, en una situación de extrema precariedad para cualquier artista. Dos personajes muy distantes, que nunca se conocieron, a pesar de haber sido contemporáneos, y que, sin embargo, se influyeron uno al otro en su obra.

Roland Barthes (1915-1980) escribió obras muy disímiles. En el comienzo de su carrera, en los años 50, bajo la influencia del pensamiento sartreano y las lecturas de Brecht, propuso una nueva crítica marxista, que se centró, en un primer momento, en las estrategias textuales de la novela contemporánea, y después se extendió al teatro y a la cultura de masas. Años más tarde, después de acercarse a la lingüística estructural, Barthes empezó a dedicarse a la semiología, que aplicó sobre todo a la comprensión de nuevas formas de significación contemporáneas, como la moda, la gastronomía y la publicidad, entre otras. Pero la semiología pronto se mostró insuficiente para abordar sistemas más complejos, como la literatura, lo que lo llevó a proponer un análisis de la lectura, conocido como análisis textual del relato. En los años 70, Barthes dejó a un lado su papel de crítico académico, publicando textos más experimentales, centrados en el aspecto subjetivo de su lectura de las obras literarias. ${ }^{1}$

1 Mucho se ha dicho sobre las diferentes "fases" de la obra de Barthes, siempre a partir de la división que él mismo propone en Roland Barthes por Roland Barthes, en que propone una fase marxista (a partir de la lectura de Marx, Brecht y Sade), una fase semiológica (a partir de Saussure), una fase textual (a partir de Sollers, Kristeva, Derrida y Lacan) y una fase moral (a partir de Nietzsche) (BARTHES, 1978, p. 155-156). Es posible también dividir su obra en grandes "proyectos" a partir de los cursos que propuso en la École Pratique de Hautes Études (EPHE), el proyecto semiológico, retórico (del análisis del relato) y experimental (basado de hecho en la lectura de Nietzsche) (PINO, 2016). 
Cuando su obra circula en el extranjero, Barthes puede ser visto como un crítico marxista, como un estricto estructuralista o como un escritor experimental, dependiendo del momento y del contexto de su recepción. Es así como en Brasil, donde sus primeras obras traducidas se relacionaban con la semiología, es recibido como un crítico estructuralista, reacio a tomar en cuenta los contextos de producción de la obra literaria. Como se trataba de un momento de lucha política de los intelectuales contra la dictadura, eso lo llevó a ser visto, en determinados círculos, como un crítico alienado, cercano, incluso, a una ideología de derecha. Ya en el caso de Portugal, para citar otro ejemplo, la traducción de sus obras coincide con la Revolución de los Claveles, lo que le permite circular como un ejemplo de liberación intelectual, especialmente a partir de la lectura de su libro El placer del texto, de su fase más experimental. (PINO; BRANDINI, 2015)

El escritor y crítico Enrique Lihn (1929-1988) ayudó a establecer el Barthes que se leyó en Chile. Al igual que Barthes, Lihn también publicó obras muy disímiles. Su trabajo más conocido es como poeta (algunas de sus obras son La pieza oscura, Poesía de Paso, El paseo ahumada), pero también publicó novelas muchos menos conocidas (como Batman en Chile, La Orquesta de Cristal y El arte de la Palabra), libros de relatos (Agua de arroz y La república independiente de Miranda) y numerosos textos críticos (conferencias, prefacios, reseñas). Fue también profesor en las dos grandes universidades del país (Universidad de Chile y Universidad Católica) y agitador literario, produciendo eventos, lecturas, polémicas y perfomances. Sus espectáculos muchas veces contaron con la colaboración de artistas visuales. Germán Marín, su gran amigo y organizador de sus ensayos, afirma que Lihn convertía el ya tenso escenario de la poesía en una carpa en llamas (LIHN, 1997, p. 12) y, por eso, decide llamar sus ensayos reunidos en 1996 El circo en llamas. Por esa multiplicidad de los campos por los que Lihn se movía, es posible tener una idea de su importancia para establecer la circulación de un autor de referencia. Aunque no fuera un crítico especialista, ni un traductor, sus lecturas de Barthes tuvieron repercusiones en muchos ámbitos, tanto en los medios literarios, como en los círculos académicos e incluso en la crítica de arte.

Ahora que ya vimos como Lihn es fundamental para Barthes, cabe entender por qué Barthes es fundamental para Lihn, no solo para su trayectoria como escritor e intelectual, sino también para su sobrevivencia en Chile del período de la dictadura. Para eso, en primer lugar, exploraremos la polémica que Lihn protagonizó sobre el estructuralismo francés, en segundo lugar, nos referiremos a la presencia de Barthes en los textos críticos de El circo en llamas, para finalmente mostrar cómo los elementos de esa crítica se encuentran de alguna forma en dos de sus relatos ("Huacho y Pochocha" y "Panorama artístico de la República Independiente de Miranda") y en el conjunto de trabajos en torno del personaje Gerardo de Pompier. 
Vivir en Chile no ha sido nunca, culturalmente hablando, vivir bien; en el día de hoy significa, quizá, la ruina. Las reducciones han llegado al límite. Un solo crítico, ninguna revista, dos salas de conferencia, un lugar de reunión, nada. Conferencia en el Encuentro de poesía chilena en Rotterdam, 1983. (LIHN, 1997, p.162)

Barthes no solo se hace presente en diversos pasajes de la narrativa o la creación literaria de Lihn en general; fue, asimismo, un tema de polémica y debate, en que se confrontó con uno de los críticos más conocidos mediáticamente en Chile. El contexto de esta polémica es el que el propio Lihn describe en la conferencia citada: un campo literario agostado por la censura y la violencia de una dictadura que duró casi tres décadas. Tal como plantea su texto, para aquel entonces en el país había "un solo crítico" y este era el sacerdote José Miguel Ibáñez Langlois, quien publicaba semanalmente sus críticas en la "Revista de libros" del diario derechista El Mercurio, bajo el pseudónimo de "Ignacio Valente", más conocido, hasta hoy, como el "cura Valente"2.

El malestar de Linh con relación al cura Valente existía desde antes del golpe militar, cuando este último criticaba los escritores de "izquierda" por relacionar militancia y literatura. Ya a fines de los años 70, el rechazo del cura Valente hacia los escritores-críticos, como Cristián Huneeus y el propio Lihn, hace que Lihn lo compare con Raymond Picard, el crítico que ataca a Roland Barthes en 1965, en Nueva crítica o nueva impostura:

nuestros críticos literarios se han esforzado por repetir, sin conocerlos, los argumentos de R. Picard contra la "nueva crítica" y/o estructuralismo con diecisiete años de atraso. Otra manera, quizá, de combatir las ideas foráneas, nacionalizando el culto a la vida en la letra y la pasión por la inspiración y el genialismo romántico. (LIHN, 1997, p. 651)

La disputa se recrudece en 1983, cuando Ibáńez Langlois publica su breve libro Sobre el estructuralismo, de apenas 73 páginas, con el objetivo de contestar a una vasta gama de pensadores relacionados al estructuralismo, como Lévi-Strauss, Lacan, Foucault y Barthes. Su gran crítica en esas páginas apunta

2 Roberto Bolaño escribe una novela abiertamente inspirada en esta figura: Nocturno de Chile, sobre un sacerdote del Opus Dei y único crítico literario de Chile en los 70-80, quien determinaba el canon literario de su tiempo sin mayores contrapesos, a falta de otros espacios culturales y periodísticos en el país. Cuenta la leyenda negra de este período que el cura Valente dio clases de marxismo a los integrantes de la Junta Militar chilena después del golpe de Estado, episodio que Bolaño también recoge en su novela, donde da vida al crítico y sacerdote "Sebastián Urrutia Lacroix". (BOLAÑO, 2000). 
al supuesto anti-subjetivismo del pensamiento estructural, que rechazaría, según Valente, el Ego en todas sus formas: el cogito, el sum, el Yo transcendental o empírico, la existencia o la persona (p. 12-13). Con relación a la crítica literaria, Ibánez Langlois afirma que los seguidores del estructuralismo se habrían dedicado a disecar el texto literario, extrayendo de esa forma también su subjetividad, que él llama "misterio":

Por último, y aunque se haya abusado tanto del misterio de la poesía (expresión que paraliza nuestra inteligencia, al sugerirle una adoración muda o una suerte de religión de la obra de arte), hoy se hace necesario evocar ese ingrediente real de misterio que rodea a la belleza, para recordar que ella no es del todo racionalizable. (IBÁÑEZ LANGLOIS, 1983, p. 53)

Lihn no tarda en publicar su respuesta. Un mes después publica un panfleto llamado Sobre el antiestructuralismo de José Miguel Ibánez Langlois. Allí se ríe de la tarea absurda de impugnación de todo el estructuralismo en 73 páginas y se pregunta si ese ataque no estará relacionado a la afirmación del poder del Opus Dei en Chile, que durante la dictadura (y hasta hoy) ocupa las esferas del poder en Chile. Al final, la crítica a "la falta de misterio" hace que el juicio dependa siempre de él, el crítico todopoderoso de la literatura chilena cuyo poder en el campo literario es parangonable al del dictador en la sociedad chilena.

Su sólido prejuicio objetivo contra el estructuralismo no actúa a favor de un cierto experimentalismo que de manera inmediata y prematura debe recordarle "el absolutismo de la forma pura, del mero procedimiento", etc. Del mismo modo, su fervor por el genio personal lo lleva rápidamente a la atribución individual de esa facultad literaria de la que habla Barthes, "hecha no de inspiraciones o de voluntades personales, sino de reglas acumuladas más allá del autor”. (LIHN, 1997, p. 487)

Finalmente, Lihn llega al argumento final para colocar Ibáńez Langlois en el lugar de su gran enemigo. El misterio de la literatura o la ausencia de la persona solo podrían significar una cosa: que Ibáñez Langlois defendía la estética realista, lo que desde siempre Lihn había combatido, como veremos a continuación:

El realismo, que no de otra manera puede nombrarse, en general, la propuesta de I.L. -lenguaje "con hombre adentro" como si el lenguaje no presupusiera al hombre, que nunca está fuera de aquél- tiende, en la creación, a divorciar la vida del lenguaje (...) El criterio de verosimilitud conlleva la desatención a la especificidad simbólica del lenguaje literario, a una cierta confusión, en nombre de la vida, del efecto de realidad con la realidad misma, al documentalismo 
y, en la tradición aristotélica, a la genericidad estricta y al gusto por las obras de masas; a un acuerdo entre las obras y lo que, en nombre del público, el creador y el crítico creen posible "por imposible que ello sea - dice Roland Barthes - histórica o científicamente”. (LIHN, 1997, p. 487-488)

\section{En el centro del fuego}

Después de describir la polémica entre Lihn y el cura Valente a propósito de los pensadores estructuralistas, vamos a observar de cerca cómo la obra de Barthes se entrecruza con la crítica de Lihn. Desde muy temprano, los críticos de Enrique Lihn reconocen su filiación a Barthes, así como a otros pensadores identificados con el estructuralismo, especialmente por las estrategias formales de sus narrativas. Es el caso de Rodrigo Cánovas, quien afirma, en 1986:

Las novelas de Lihn mantienen un estrecho diálogo con el pensamiento estructuralista. El proyecto novelesco de escribir una obra disforme, de componer un cuerpo hecho de retazos, de organizar de un modo ambiguo el mundo ficticio está creado a la luz de los escritos franceses. La idea de Lihn de retrotraer la contingencia histórica a los modelos lingüisticos que la constituyen y de establecer un registro paródico de las distintas versiones del poder realizadas por el lenguaje (él mismo, un signo represor por excelencia), tienen un claro correlato, por ejemplo, en los diversos escritos de Barthes, Kristeva y Foucault dedicados a la relación entre el lenguaje, el poder y el conocimiento. (CÁNOVAS, 1986, p. 16, pasajes en cursiva nuestros)

La "obra disforme hecha de retazos" no es una referencia clara a los pensadores estructuralistas, sino más bien a las obras literarias que ellos analizaban. Es el caso de la obra Mobile, de Michel Butor, hecha de diversos fragmentos y objetos, que es exaltada por Barthes en su libro Ensayos criticos. Con lo del "registro paródico", Cánovas probablemente se refiere a los textos de Barthes en que defiende los límites del uso político del lenguaje, como, por ejemplo, "La lección inaugural”, de 1978. Allí, él afirma que la lengua nos obliga a decir de determinada manera: por más que queramos oponernos al sistema, nuestro discurso estará delimitado por las formas de decir de ese sistema. La lengua está al servicio del poder. Como no podemos crear otra lengua, solo resta "hacerle trampas a la lengua", producir distancia (como Brecht), usarla para producir parodia (BARTHES, 2003).

Pero el uso de Barthes no se limita a ese registro paródico de sus narrativas apuntado por Cánovas. Barthes es abundantemente citado en la producción crítica de Lihn, a partir de textos de diferentes momentos, pero que orbitan en torno de algunas ideas en común, como veremos. 
Para entender las discusiones que Lihn establece con Barthes, es importante conocer el contexto de sus críticas. Buena parte de los ensayos de El circo en llamas se refiere a su rechazo a una estética realista, propia de los escritores criollistas chilenos a partir de los años 30 (OVIEDO, 1998, p. 26), como vimos en la polémica con el cura Valente. El criollismo no es un movimiento definido, sino una forma de agrupar una serie de propuestas que convergen hacia un nuevo realismo, que representa los aspectos físicos, modos de vida, usos de lenguaje y tradiciones culturales poco conocidas de América Latina. Dentro del gran paraguas del criollismo, es posible incluir al regionalismo de los años 30 , pero también a autores posteriores, que parten de una base mimética y regional, pero revisitada, como los narradores del boom latinoamericano o incluso poetas preocupados en cantar la realidad de la "tierra", como Pablo Neruda.

En los años 60, una de las grandes preocupaciones de Lihn pasaba por distinguir su obra y la de sus compañeros de generación, de una "órbita criollista" que ya se extendía por demasiado tiempo en la creación y la crítica literaria chilena, como podemos ver en la conferencia "Momentos esenciales de la poesía chilena”, proferida en 1969 :

Creo que si nuestra generación fracasara poéticamente ello podría deberse (y se debe en parte en el caso de Chile) al empeńo de repetir o permanecer en la órbita americanista, romántico-naturalista y criollista en que giraron los grandes poetas neorománticos o los grandes poetas de la primera vanguardia. Ni el alma o la raza, si se quiere, del hombre americano, ni la naturaleza son nuestras preocupaciones definitorias, sino más bien el hombre mudable, existencial que padece en Latinoamérica mucho menos ya entre los brazos de divinidades telúricas, devoradoras y fatales, que en curso de una vida amenazada permanentemente por la implenitud, la frustración y fracaso individuales $y$ colectivos. (LIHN, 1997, p. 60)

Roland Barthes todavía no aparece de forma explícita en sus ensayos, pero ya podemos identificar una confluencia entre sus ideas. Según Lihn en el pasaje citado, la preocupación definitoria de su generación debería ser el padecimiento existencial del hombre latinoamericano, amenazado por el fracaso individual y colectivo. Esa formulación de inspiración lukacsiana, es sin duda también la base del primer libro crítico de Roland Barthes, El grado cero de la escritura (1953). Allí, Barthes también describe la literatura burguesa como el relato de un fracaso, aunque para él esa "implenitud" no se limita al destino de los personajes, sino también del escritor. De la misma forma que los personajes no pueden contra la estructura del sistema burgués, el escritor tampoco puede contra la estructura de la lengua: está condenado a repetir sus formas o practicar alguna forma silencio (BARTHES, 2011, p. 56). 
Las referencias de Barthes en ese momento son sobre todo la obra de Camus y de Beckett, en que los personajes son anulados por el sistema (que los excluye y los condena), donde el lenguaje es también llevado a su mínima expresión (con frases cortas, estilo seco, muy distante de la pompa literaria del realismo de Balzac, por ejemplo) y donde el lector, inevitablemente, es llevado a una lectura más activa, en que él debe poner las palabras que ya no son usadas por el escritor. Más adelante, veremos cómo Lihn también usa esa estrategia de búsqueda de un mutismo en su relato "Huacho y Pochocha", aunque de forma muy diferente a lo practicado por Camus.

Aunque Barthes ya aparece en muchos ensayos de Lihn de los años 60, su presencia aumenta considerablemente después del golpe militar. La crítica de Lihn a la estética criollista ahora adquiría un nuevo sentido: en un lugar donde toda la producción artística y literaria era vigilada, era necesario alejarse de una representación directa de la realidad, como es posible observar en este artículo de 1985:

El golpe militar, que no desmanteló la producción poética, dividió a los escritores en dos grupos, fracturando la tradición poética chilena, en un cierto sentido. Forman uno de esos grupos los que han continuado o iniciado su obra en el exilio, muchos de ellos entrampados en la facilidad del panfleto, y, segundo, quienes se quedaron en el país completando su obra o iniciándola un poco más silenciosamente o subiendo más el diapasón, pero del discurso connotativo, que obliga a una lectura creativa. (LIHN, 1997, p. 184)

Aquí la mención a Barthes se reconoce por la alusión a un discurso "connotativo". Aunque la "connotación" sea un término propuesto inicialmente por la lingüística estructural (especificamente por Hjelmslev), fue retomado por Barthes en sus Elementos de semiología, en principio para ayudarlo a describir los sistemas de significación contemporáneos. Sin embargo, ya en su definición, Barthes reconoce que se trata de un concepto que sirve específicamente a la literatura: "un sistema connotado es un sistema cuyo plano de la expresión está constituido por un sistema de significación; los casos corrientes de connotación estarán evidentemente constituidos por los sistemas complejos cuyo primer sistema lo forma el lenguaje articulado (es, por ejemplo, el caso de la literatura)" (BARTHES, 1993, p. 76). Más tarde, en 1970 , en el libro $S / Z$, Barthes retoma el concepto de una forma completamente diferente, transformándolo en la base de su propuesta de análisis textual. En esa nueva concepción, la connotación es una red de relaciones, operada por el lector, pero a partir del texto:

¿Qué es, pues, una connotación? Definicionalmente, es una determinación, una relación, una anáfora, un rasgo que tiene el poder de referirse a menciones anteriores, ulteriores o exteriores, a otros lugares del texto (o de otro texto): 
no hay que restringir en nada esa relación, que puede ser llamada de diversas maneras (función o índice, por ejemplo), siempre que no se confunda connotación y asociación de ideas: ésta remite al sistema de un sujeto mientras que aquella es una correlación inmanente al texto, a los textos; o si se prefiere, es una asociación operada por el texto-sujeto al interior de su propio sistema. (BARTHES, 2004, p. 5)

Así, el valor al texto se da no por lo que el texto representa, sino por la actividad del lector. Sin duda el concepto ayuda en momentos de censura, pero también refuerza una estética que ya se encontraba desde antes, en sus propuestas anteriores de escritura del fracaso o de la implenitud.

En esa misma línea, se encuentran las reflexiones del texto de Lihn "Juan Luis Martínez. La nueva novela", una curiosa reseña que se niega a hacer cualquier referencia al libro reseñado, y que propone, en cambio, múltiples citas a la obra de Barthes y otros autores cercanos, como Genette y Blanchot. Esa subversión se justifica porque el libro-objeto de Juan Luis Martínez contiene en sí mismo múltiples citas de diferentes escritores, además de insertos de diario, fórmulas matemáticas, dibujos e incluso diferentes ejercicios para el lector, como pasatiempos y preguntas sobre el propio libro que está leyendo (MARTÍNEZ, 1985). Lihn propone una especie de pastiche crítico del libro. Allí vemos referencias, por ejemplo, al clásico texto de Barthes "La muerte del autor", donde Barthes afirma que el nacimiento de ese nuevo lector activo tiene que pagarse con la muerte del autor. El libro de Martínez, hecho supuestamente con recortes de otros libros (o por lo menos recortes de lo que podría ser un libro de otro) sin duda pone en cuestión la existencia de un autor que haya creado el contenido de su libro:

La letra es lo único real. El sujeto de los textos de Juan Luis Martínez es solo yo de papel, denominación que inventó Barthes para encarecer, justamente, la noción de texto, y detrás de él (¿de quién?), en l'imminence d’une révélation qui ne se produit pas, todos escriben. (LIHN, 1997, p. 175)

Para Barthes, el "todos escriben" no se aplicaría solamente a una obra experimental como la de Juan Luis Martínez: la red de relaciones a la que nos referimos no tiene origen, solo un destino, el lector. Pero La nueva novela lleva la propuesta de Barthes a otra dimensión: en el libro, incluso el nombre de autor aparece tachado en la portada "Juan Luis Martínez" junto al de su padre, "Juan de Dios Martínez". No hay origen posible, ni siquiera hay origen del origen ("el padre del autor"). Eso lleva a Lihn a incorporar a su reseña un pasaje de otro artículo de Barthes ("De la obra al texto", de 1971), donde él se refiere justamente a la negación de la figura del padre de una obra: 
El orden de La nueva novela, sin la unicidad de un sujeto que lo rige - ¡alguien? -, se impone autoritariamente, pero está intrínsecamente desautorizado. Porque el autor- R.B. - reputado por padre y propietario de su obra, está aqui denegado, sus imposiciones no se fundan en ningún derecho. El texto se lee sin la inscripción del padre. La metáfora del texto se despega una vez más aqui de la metáfora de la obra: esta remite a la imagen de un organismo que crece por expansión, por desarrollo (palabra significativamente ambigua: biológica y retórica) la metáfora del texto es la red; si el texto se amplia, es por efecto de la combinatoria, de una sistemática (imagen cercana, por otra parte, a los puntos de vista de la biología actual sobre el ser vivo); ningún respeto vital se debe, pues, al texto; puede ser roto (por otra parte es lo que hacia la Edad Media con dos textos, sin embargo, autoritarios: La Sagrada Escritura y Aristóteles). En una mímesis del libro, la mímesis de la autoridad de los libros totales como ésos, no es inocente. Proviene de autoridades varias, localizables o no, verdaderas o apócrifas, pero la falta de respeto al texto, hecho de roturas, lo compromete desde adentro, se extiende desde el modo de citar al contenido de las citas y a la forma en que la diagramación de las mismas atenta contra los criterios de verosimilitud y el concepto de la verdad.

(LIHN, 1997. La parte en cursiva es del texto de Barthes "De la obra al texto", BARTHES, 1994, p. 78-79).

Pero Lihn no se limita a reseñar el libro de Martínez. Además de su pastiche crítico, él también hace su propio libro-objeto: Derechos de autor, de 1981. El título escogido para su libro ya muestra un diálogo con ese mismo Barthes de 1970, de exaltación del lector y de crítica a la figura del autor. Claramente se trata de un título irónico: Lihn está muy lejos de referirse a los derechos de autor, de hecho, los está subvirtiendo de forma muy explícita. El libro es un collage de recortes de diarios, de textos de otros autores, fotografías, manuscritos y en el medio de todo eso, algunos textos críticos de Lihn, publicados en El circo en llamas. Es como si Lihn construyera materialmente la red de relaciones a la que se refiere Barthes en $S / Z$, proclamando de forma explícita la muerte de sí mismo, el supuesto Enrique Lihn que no escribió el libro Derechos de Autor y que, por tanto, no tiene derechos sobre su obra. En efecto, el autor del libro (indicado con letra imprenta y manuscrita una sobre la otra) migra hacia la función de editor del libro, publicado por una enigmática editora, llamada "Yo editores".

$\mathrm{Al}$ interior de libro, encontramos un "Tercer borrador para una conferencia dictada en el Instituto de Cultura Hispánica”, en el que propone una reflexión sobre sí mismo, en particular, sobre sus novelas, poco divulgadas y ni siquiera publicadas en Chile (La orquesta de cristal fue publicada en Buenos Aires y El arte de la palabra en Barcelona). Allí, Barthes nuevamente aparece como un gran referencial teórico, pero de otra manera que en los textos anteriores. Según Lihn, el rechazo hacia sus novelas se debería a su 
"antimundonovismo" (p. 397), es decir, la falta de referencialidad a la realidad latinoamericana y al hecho de no haberse subido al "ómnibus del fait divers", o sea a no centrarse en una gran intriga, sino en la reflexión crítica. Barthes ahí sirve para justificar un discurso que es al mismo tiempo crítico y ficcional:

Un aspecto, quizás el único que me atrae, de la literatura - lo asocio con la alegría, la sensualidad y la tortura de escribir - es la ocasión que la práctica de aquella ofrece, de pensarla. Pensar a partir de la literatura, en ella, con ella y sobre ella, dentro, pues, de la literatura misma. Es algo que (como algunos de ustedes saben muy bien) explicó Roland Barthes, en el lejano 1959, en dos páginas tituladas "Literatura y metalenguaje", como "la voluntad heroica-dijo, respecto de Mallarmé - de confundir en una misma sustancia escrita la literatura y el pensamiento sobre la literatura". (LIHN 1981; LIHN, 1997, p. 568)

En el texto aludido Barthes está todavía muy lejos del análisis textual, del texto en red e incluso de la muerte del autor. Pero está llegando poco a poco a esa idea al identificar que el autor ya no es uno, sino dos: el autor que escribe y el que piensa sobre lo que escribe. Después de Mallarmé, el autor ya no es simplemente un autor de literatura, sino un autor-crítico (¿un autor que va contra sí mismo? ¿un autor suicida?).

Como veremos en la parte final de este artículo, Lihn aquí opera dos elementos que estarán presentes en sus relatos y performances: el desdoblamiento y la tercera forma. En Derechos de autor, Lihn se desdobla de forma crítica: escribe un texto sobre sus novelas. Pero ese desdoblamiento también tiene un lado literario: en todos los textos en torno al personaje Gerardo de Pompier, Lihn se transforma de hecho en otro, con otro nombre, con otra visión sobre la literatura, con otro aspecto físico, incluso, pero con su propio cuerpo.

Por su parte la "tercera forma" es el nombre que Barthes usa en 1978 para referirse a la búsqueda de un nuevo género, que no sería ni ensayo ni novela, que habría sido inaugurado por En busca del tiempo perdido, de Marcel Proust (BARTHES, 1994, p. 330) y que él mismo hubiera querido practicar, pero no tuvo tiempo de hacerlo3. Lihn de hecho también se refiere a ese género híbrido, que él llama simplemente "discurso literario":

Mi costumbre de hacer poesía nació mezclada, en Bellas Artes, con la práctica de otros géneros: el cuento, la novela, el ensayo crítico. Todas estas especies pertenecen para mí a un género que las contiene todas y que, a veces, puede manifestarse por sí mismo, sin intermediarios: el discurso literario. La instancia crítica es para mí inmanente a la literatura. Crítica de la sociedad, crítica de

3 Barthes murió en 1980, mientras escribía esa “tercera forma”, a la que se refiere en el curso La preparación de la novela, publicado en 2002. 
la cultura y, en último término, crítica de la realidad. No hago de la crítica un tema literario, porque creo que un cierto modo de hacer literatura, al que aspiro, es por sí una acción crítica. (LIHN 1981; LIHN 1997, p. 395-396)

De una forma muy distinta a Proust, "Panorama artístico de la República Independiente de Miranda" es sin duda un texto de la "tercera forma", que se constituye claramente como ensayo, pero un ensayo que no se encuentra en el espacio tiempo de nuestra realidad, sino en una dimensión ficcional, como veremos a continuación.

\section{Del silencio al desdoblamiento}

Algunos de estos diálogos críticos y puntualizaciones de las lecturas lihneanas de Barthes ya despuntan de otras formas en dos relatos y un singular happening del autor, cuya trayectoria literaria se desarrolló paralelamente a su interés por las artes visuales, ámbitos que se entrecruzan en su trabajo.

Uno de esos cuentos es quizá el que más fama tiene entre sus narraciones: "Huacho y Pochocha", publicado en Agua de arroz, de 1964, anterior a la mayoría de los textos analizados aquí y sobre todo distante de la discusión crítica en torno del análisis de la lectura y de la muerte del autor, que son el centro del interés de Lihn en la obra de Barthes. Sin embargo, vemos en él -como ya lo apuntamos- ecos del Grado cero de la escritura, de 1953. Hasta el momento, no vemos en los textos de Lihn citas directas a ese libro, lo que no indica que no lo haya leído o que no haya escuchado relatos sobre su contenido.

El cuento de Lihn parte de una historia que nunca se concretiza y por lo tanto es en sí el relato de varios fracasos, entre ellos, el fracaso de contar una historia. Así dice en la frase inicial: "De la historia de amor de Huacho y Pochocha subsisten las huellas conmovedoras que me fuerzan, periódicamente, a aventurarme en una empresa imposible: reconstituirla" (LIHN, 2016, p. 49). No se trata aquí del "viejo cuento de cómo se escribe un cuento", según relato de Lihn aludido por Roberto Careaga en su prólogo a los Cuentos reunidos (p. 12), sino del cuento de cómo no se escribe un cuento. El narrador intenta reconstituir esa historia amor sin jamás realmente hacerlo. Para eso, buscará inspiración en supuestas personas concretas que él conoció y que podrían servir de base para Huacho y Pochocha, pero su memoria nunca recuerda todo y las personas al final no podrían ser los personajes de la historia:

$\mathrm{Al}$ amanecer, ingurgité el último trago de la noche y me despedí -para siempre- de mi nuevo amigo. Seguramente quise saber su nombre. Él me lo articularía con su voz estropajosa. Acaso dijo Huacho; pero la verdad, no estoy seguro de recordar cómo se llamaba. (p. 60) 
El narrador nunca llega a constituir los personajes que son presentados apenas como lo que podrían haber sido, pero nunca llegaron a ser. En todo caso, eso que podrían haber sido también es un fracaso: en sus trabajos, en su salud, en su relación con el mundo. Lo único que esos personajes realmente habrían hecho en su vida sería tener la relación amorosa entre los dos. Pero, al final, Pochocha, enferma, llegaría a un momento de lucidez y se daría cuenta que incluso su relación con Huacho, lo que le daba sentido a su existencia, también no pasaba de un fracaso:

Cuando Pochocha pierde en su oído los pasos casi livianos de Huacho -el tropezar de sus grandes pies en los adoquines-, comprende que ha cometido el error más grande de su vida. Ve en todas partes platos sucios, a medio comer, que se acercan y se alejan de ella, por sí solos, con violencia. En el vacío en que desvaría, todo adquiere la blandura de alimentos corrompidos, las sábanas hieden. La tierra misma se licua, grasa, aceitosa y pútrida, las manos cucharean, el cuerpo es todo boca. Y Huacho... Un punto a la distancia. Un punto muerto.

Lo llama sin voz. El catre de pirinola empieza a bambolearse, desatracado, como si se lo llevara la corriente. Ella se alza en un espasmo. Va a caer al suelo, pero ya no lo sabe. Está a salvo de todo peligro. (p. 95)

Y así Pochocha se muere de forma lúcida, pero nada puede decir, porque su llamado no tiene voz. Así vemos como ese relato en curso de una vida es amenazado permanentemente por la "implenitud, la frustración y fracaso", como afirmaba Lihn en su ensayo "Momentos esenciales de la poesía chilena". Pero desde el inicio, el fracaso aquí no se limita a la existencia de los personajes: el narrador-escritor nunca llega a asumirlo y su historia nunca se concretiza. Pochocha no logra decir lo que finalmente descubre (que la historia de amor no tiene sentido) y va a morir, pero, de hecho, no se muere. El cuento se termina en el más absoluto silencio, en la estela de lo defendido para la literatura contemporánea por Barthes en El grado cero de la escritura.

Como se planteaba en las páginas anteriores, hay otro relato en que se revelan estos "lihneamientos" barthesianos. Se trata de "Panorama artístico de la República Independiente de Miranda", en que Lihn practica la "tercera forma" a la que se refiere Barthes, un nuevo género que oscila entre el ensayo y la ficción, y que confunde en una misma sustancia escrita la literatura y el pensamiento sobre la literatura (o en este caso, el arte y pensamiento sobre el arte). La hibridez de este cuento no se limita a la mezcla entre ensayo y ficción. Inscrito en el libro La república independiente de Miranda, en el que varios cuentos giran en torno de ese país ficcional, forma parte de un sistema que posibilita la lectura intratextual, generando el contorno de un cuento-novela-crítica. 
Desde el párrafo inicial, podemos observar cómo el cuento se coloca claramente en el registro del ensayo, ya que comienza con una cita filosófica (Hegel) y plantea el uso de una voz impersonal:

La idea de la muerte del arte, cara a Hegel, ha resucitado siempre que el [arte] de Miranda ha atraído la atención de historiadores y críticos de arte foráneos, de paso en nuestro país, por invitación del Ministerio de Defensa de la Cultura Autóctona.

Pero no debe confundirse el acta de defunción con un mal diagnóstico.

Por muerte del arte debe entenderse la superación del arte y no necesariamente su extinción.

De la misma manera si Dios muere, teológicamente hablando, lo hace para mayor gloria de sí mismo. (Lihn 2016, p. 249)

Más adelante, podemos observar que el "narrador" del texto, antes impersonal, se coloca también en primera persona del plural, variación común en muchos textos de naturaleza intelectual y no ficcional. La ficción, salvo excepciones, es narrada desde la tercera o la primera persona del singular, como muchos críticos ya constataron, incluso Barthes5. Ese "nosotros", como sabemos más adelante en el relato no tiene identidad definida, pero sí una profesión, son "historiadores del arte" (p. 285): es decir, personajes que se expresan en el registro del ensayo.

Los historiadores del arte/narradores hacen en el relato una descripción del arte de Miranda, con el objetivo de demostrar su idea inicial, la de la "muerte del arte" como "superación del arte". En Miranda, una obvia alegoría de Chile durante la dictadura militar, el arte se rige por una necesidad imperiosa de realismo y es controlada no por los impulsos de los propios artistas, sino por "estetas que manejan categorías y criterios de verosimilitud en primer grado" (p. 250) (una clara referencia al "único" crítico literario durante la dictadura). Así, los considerados grandes artistas de Miranda son aquellos que de alguna forma retratan la "realidad nacional", sus paisajes, sus personajes, su naturaleza; los ochenta profesores y estudiantes rebeldes de la Escuela de Bellas Artes "se negaban a ver las cosas como son (...), pintando mamarrachos" (p. 274-275), por lo que se les obliga a salir del país en un carguero, en una situación de extrema precariedad.

\footnotetext{
4 En el original está escrito "La idea de la muerte del arte, cara a Hegel, ha resucitado siempre que el de Miranda”. Creemos que hubo un error en la edición y la palabra arte fue suprimida por accidente, pero es apenas una suposición, puesto que falta un sujeto en la frase.

5 Tal vez el estudio más conocido a respecto de las voces del relato sea el de Genette en "Discurso del relato" (GENETTE, 1972). El ensayo El grado cero de la escritura, de Barthes, también tiene una reflexión inaugural sobre el uso de las voces en el relato realista ("La escritura de la novela").
} 
Así, el arte abstracto o vanguardista no es practicable en Miranda: solo cabe la opción de seguir las consignas de los estetas oficiales y practicar el realismo. Sin embargo, instintivamente, los artistas de Miranda siguen el camino de la negación del arte, en que no hace falta obra y, por lo tanto, esta no puede ser censurada. Es el caso de la Galería Galaxia, en la que "se procedió a dibujar con un lápiz de carnicero el cuerpo desnudo del artista Samuel Gordillo las distintas presas en que se troza el cuerpo de un animal en el matadero" (p. 282). Sin que se supiera cómo, la carne de Gordillo se trozaba por sí sola, siguiendo las indicaciones del diseño. En otro ejemplo de negación del arte, Enrique Volvox, el coreógrafo del grupo Engranaje, de "bailarines semióticos"6, se arroja al río Calle y a continuación todos sus bailarines se ahogan en sus casas sin auxilio de ningún artefacto, gas o agua. Finalmente, el último ejemplo es del escultor hiperrealista Marcial Wallegren, quien desaparece y deja en su taller un autorretrato en tamaño natural, vestido con sus propias ropas (una autopsia "ha dejado claro que no se trata de un cadáver", p. 283).

En un lugar donde el arte debe imitar la realidad obligatoriamente, la realidad empieza a constituir el arte. No sería la primera vez que el fenómeno ocurre en Miranda (país donde nadie recuerda haber tenido otro gobernante que el Gran Protector): el cubismo allí surge antes que en los países europeos, porque la propia realidad empieza a adquirir formas cúbicas y cónicas. El papel del artista de Miranda debe ser entonces, no crear obras artísticas, sino intervenir en la realidad ${ }^{7}$, produciendo algo que merece (o no) ser plasmado en registros documentales.

Los historiadores del arte perciben ese gran cambio y sus consecuencias: finalmente, si el arte interviene en la realidad, la realidad puede cambiar y poner en peligro el orden instituido en Miranda. Así, es posible que un escultor haga una obra en carne y hueso del Gran Protector y después se le ocurra arrojarla al mar. Esta constatación coloca a los narradores del relato en una extraña posición, ya que son ellos los responsables por interpretar el arte contenido en la intervención y son ellos, por lo tanto, los que de alguna manera van a contestar al orden, al gobierno y a los estetas de Miranda. La negación del arte de los artistas solo tiene sentido con la afirmación del arte por los críticos. Y así, los historiadores del arte perciben que corren peligro, como los alumnos y profesores de la Escuela de Bellas Artes obligados a partir al exilio: "Los historiadores del arte, en tanto, debiéramos consultar, prudentemente, algunos textos de magia a la búsqueda de la estética de un mañana que habrá que justificar ante las autoridades antes de huir al extranjero" (p. 285).

6 Un claro guiño a la obra de Barthes.

7 Este es de hecho el objetivo de muchos artistas de neovanguardia chilenos en los años 80 , muy cercanos a Enrique Lihn. Cito, entre ellos, el trabajo de Lotty Rosenfeld, que intervenía en el asfalto de las calles, produciendo cruces donde antes había líneas blancas, recordando así a los ejecutados por el Régimen Militar. 
El relato termina con la afirmación de la interdependencia entre arte y crítica, que también está en la base de este texto y su hibridez textual. De esta manera, Lihn explora al extremo "la voluntad heroica de confundir en una misma sustancia escrita la literatura y el pensamiento sobre la literatura", que lo había inspirado en las obras de Barthes.

Para finalizar ese recorrido y ejemplificar otra dimensión de la relación Lihn/Barthes, nos referiremos a un conjunto de obras en las que aparece el personaje Gerardo de Pompier. Creado por Lihn junto a Germán Marín como un sujeto apócrifo que ejerce de columnista en la revista Cormorán, editada por los dos amigos entre los años 1969 y $1971^{8}$. Además de columnista, el personaje se va a convertir en una figura recurrente en el trabajo del autor; como personaje de sus novelas La Orquesta de Cristal y El arte de la palabra y del happening entre fines de 1977 y comienzos de 1978, cuyo registro aparece en un cuadernillo titulado Lihn \& Pompier.

Se trata de un personaje caricaturesco, sus rasgos y discursos se 'nutren' del discurso de la Belle Epoque francesa, aunque no por eso es extranjero: Pompier exhibe las características de ese sujeto hispanoamericano que habita como forastero en una cultura ambivalente entre lo mestizo y lo híbrido.

En sus artículos publicados en Cormorán el personaje “(...) opinará sobre la situación política del país y establecerá refinadas ironías cargadas de erudición y sarcasmo" (BARRIENTOS, 2003, p. 111). A partir de esas ironías, Lihn desarrolla la teoría de la cháchara, fundada en el concepto de Jacques Lacan, la 'palabra vacía', la palabra del paciente que no logra referirse ni decir nada de lo que ocurre realmente, sino más bien 'rondar' estos hechos, de tal manera que se oculta el trauma y solo lo refiere enmascaradamente (LIHN, 1981). Asimismo, Pompier es una palabra vacía, no logra referirse a nada de lo que ocurre realmente, porque de lo que ocurre (la dictadura, la represión), no se puede hablar. En ese sentido, su figura es alegórica, en tanto sus estrategias de articulación y su discurso registran cierto duelo traumático de una escritura que, como bien señala Adriana Valdés, “(...) da cuenta de las circunstancias de silenciamiento en la cual fue escrita” (VALDÉS 1979 , p. 41), circunscribiéndose a distintos aspectos de la cultura chilena e hispanoamericana, tanto en términos contextuales como estéticos.

Veamos aquí un ejemplo de esa cháchara, del happening Lihn \& Pompier, de 1978, donde Lihn se disfraza de Pompier:

8 Sobre los detalles de la historia de personajes ver "Nadie habla, nadie escribe Apunte final sobre Lihn \& Pompier" (LANGE, 2010, p. 81-101)

9 En ésta, al personaje se le cambia leve y circunstancialmente el nombre (Pompier por Pompffier) sin que esto tenga mayor incidencia en el texto. 
Todos los hombres no son iguales, y la igualación teórica de sus / derechos / reconoce implícitamente el mérito de la desigualdad: fuente de / conflicto / pero que hace igualmente posible la división del trabajo, / sobre la cual descansa la Sociedad Civilizada. / Es un don del cielo el que la igualdad de derecho descienda sobre / tantas cabezas distintas: / y quizá no pertenecemos, señores, virtualmente a la misma especie, / pero yo me declaro acérrimo partidario de la idea de que / todos los hombres son humanos, / tesis defendida por Fray Bartolomé de las Casas ante los tribunales / de Cádiz / (un bello gesto ligeramente anarquista). / Pero lo que se llama iguales no lo son ni siquiera los gemelos / idénticos nacidos del mismo óvulo. / para no hablar de los gemelos ordinarios que proceden de huevos distintos. / Si algunos débiles mentales no pueden beneficiarse de ninguna especie / de educación avanzada / hay que racionalizar la producción de esas rémoras / por medio de la eugenesia como actitud sicológica / Sin la igualdad normal, la Sociedad, homogénea como una bola / de billar dejaría redondamente de moverse por sí misma, petrificada e inútil como un cero a la izquierda. / ¡Piénsese en lo que ocurriría a una Sociedad formada sólo por hombres / semejantes en todos sus aspectos! ¿Podría un mundo así tener granjas y fábricas, aeroplanos y submarinos, / orquestas sinfónicas e investigación científica? (LIHN, 1978)

El discurso en el inicio gira en torno de una idea (los hombres no son iguales), sin llegar a una conclusión, repitiendo la misma información a partir de elementos de erudición que nada aportan a los argumentos (por ejemplo, "yo me declaro acérrimo partidario de la idea de que todos los hombres son humanos, tesis defendida por Fray Bartolomé de las Casas ante los tribunales de Cádiz"). El lenguaje utilizado por Lihn en el texto corresponde a una imitación paródica de lenguajes y modales utilizados por distintas esferas de poder. Este lenguaje, que en su uso 'normal' refiere la actitud de un discurso autoritario, devela ciertas 'anomalías' de lo que es recibido y comprendido por escritores, críticos y lectores como un lenguaje normal y válido.

Así, vemos como Lihn aquí se desdobla, transformándose supuestamente en dos sujetos: el escritor Enrique Lihn y el crítico Gerardo de Pompier. Pero ese desdoblamiento es mucho más complejo de lo que parece. Gracias al carácter vacío de la "cháchara" de Pompier, es imposible asumirlo como crítico: el lector así es obligado a tomar ese lugar y decir aquello en torno de lo cual se gira y no se dice (el trauma). Y así, el desdoblamiento es doble: desdoblamiento del autor y del lector. Barthes desarrollará esos desdoblamientos múltiples en sus obras experimentales, como Roland Barthes por Roland Barthes y, sobre todo, Fragmentos de un discurso amoroso, aunque no hay ningún registro de que Lihn las haya leído. Pero estaba claro que iban por el mismo camino.

La historia de Lihn y Barthes es una historia en curso, de la que hay mucho más que descubrir. Una publicación reciente (LIHN, 2020) de nuevos ensayos críticos y la reedición reciente de sus obras poéticas y narrativas por la Editora Universidad Diego Portales, permiten ver que cada vez más se conoce y 
se leen las obras de Lihn, quien era el animador del circo en los años 70 y 80 en Chile y sigue de alguna manera siéndolo, pero en un nuevo circo, con nuevos traumas. En el circo de la dictadura, Barthes era el crítico de estructuralista que valorizaba la parodia y el distanciamiento y permitía analizar las obras literaria sin pasar por la representación directa de la realidad. En el nuevo circo, Barthes sigue siendo el crítico que ayudó a una generación a sobrevivir durante la dictadura, pero ahora también es posible verlo como un escritor que practicaba (tan distante y al mismo tiempo tan cerca) las mismas acrobacias (la escritura del silencio, la distancia, el desdoblamiento, la tercera forma).

\section{Referencias}

BARRIENTOS, Óscar. "Enrique Lihn, las aristas de un narrador sorprendente" en Mapocho, 53 (2003).

BARTHES, Roland. El grado cero de la escritura y Nuevos ensayos críticos. Trad. Nicolás Rosa. Buenos Aires: Siglo XXI, 2011.

BARTHES, Roland. La aventura semiológica. Trad.: Ramón Alcalde. Barcelona: Paidós, 1993.

BARTHES, Roland. S/Z. Trad.: Nicolás Rosa. Buenos Aires: Siglo XXI editores, 2004.

BARTHES, Roland. "De la obra al texto". El susurro del lenguaje. Trad. C. Fernández Medrano. Barcelona: Paidós, 1994.

BARTHES, Roland. "Mucho tiempo he estado acostándome temprano". El susurro del lenguaje. Trad. C. Fernández Medrano. Barcelona: Paidós, 1994.

BARTHES, Roland. Roland Barthes por Roland Barthes. Trad. Julieta Sucre. Barcelona: Kairos, 1978.

BARTHES, Roland. El placer del texto y Lección inaugural de la cátedra de semiología literaria del Collège de France. Trad. Nicolás Rosa y Oscar Terán. Buenos Aires, Siglo XXI, 2003.

BOLAÑO, Roberto. Nocturno de Chile. Barcelona: Anagrama, 2000.

CÁNOVAS, Rodrigo. Lihn, Zurita, Ictus, Radrigán: literatura chilena y experiencia autoritaria. Santiago: Ediciones Ainavillo, 1986.

IBÁÑEZ LANGLOIS, José Miguel. Sobre el estructuralismo, de Ediciones Universidad Católica de Chile. 1983.

GENETTE, Gérard. Figures III. Paris: Seuil, 1972. 
LANGE, Francisca. "Nadie habla, nadie escribe. Apunte final sobre Lihn \& Pompier". Notas Visuales. Fronteras entre imagen y escritura. Santiago de Chile: Pontificia Universidad Católica, Instituto de Estética / Metales Pesados, 2010.

LIHN, Enrique. Lihn \& Pompier. Santiago. Departamento de Estudios Humanísticos, 1978.

LIHN, Enrique. ¿Qué nos ha dado con Kafka? Santiago, Overol, 2020.

LIHN, Enrique. El circo en llamas. Santiago de Chile: LOM, 1997.

LIHN, Enrique. Cuentos Reunidos. Santiago: Ediciones de la Universidad Diego Portales, 2016.

LIHN, Enrique. Derechos de autor. Santiago: Yo Editores, 1981.

OVIEDO, José Miguel. Reflexiones sobre el "criollismo" y su desarrollo en Chile. Anales de Literatura Hispanoamericana, n. 27, p. 25-34, 1998.

MARTÍNEZ, Juan Luis. La nueva novela. Santiago: Ediciones Archivo, 1985.

PINO, Claudia Amigo. De l'incompréhension, de la création, des œillets : Barthes au Brésil et au Portugal. Revue Roland Barthes, n. 2, 2015.

PINO, Claudia Amigo. Genèse d'une critique magique. In: Bertrand, J.P. Roland Barthes: continuités. Paris: Christian Bourgois, 2016.

VALDÉS, Adriana. Escritura y silenciamiento. Mensaje, (XXVII), nº 276, 1979.

Claudia Amigo Pino. Profesora de literatura francesa na Universidad de São Paulo. Doctora en Letras por la USP. Actualmente investiga la circulación de Roland Barthes en la literatura y la crítica latinoamericanas. Ha publicado los libros Roland Barthes, a aventura do romance (2015) y organizado los libros Roland Barthes Plural (2017) y Novamente Roland Barthes (2018), junto a Laura Brandini, Márcio Venício Barbosa y Sílvia Brito, entre otras publicaciones.

E-mail: hadazul@usp.br

Francisca Lange. Profesora y directora de la Escuela de Literatura de la Universidad Finis Terrae. Doctora en Filosofía, con mención en Teoría y Estética del arte (U de Chile). Ha trabajado en distintas universidades como profesora de Teoría Literaria y Estética e investigado en temas como la construcción de la infancia y la masculinidad y el discurso autorreflexivo de distintxs autores chilenos, temas sobre los que ha publicado diferentes artículos, principalmente sobre la obra de Enrique Lihn y Cristián Huneeus. Es autora de la antología Deicinueve. Poetas chilenos de los noventa (2006).

E-mail: flange@uft.cl 